\title{
PENGABDIAN EVALUASI AKSEPTOR INTRA UTERINE DEVICE (IUD) INTERVAL DI MASA PANDEMI
}

\author{
Ivanna Beru Brahmana1), Shanti Wardaningsih") \\ 1)Bagian Obstetri \& Ginekologi, Program Studi Pendidikan Dokter, Fakultas Kedokteran \& IImu Kesehatan, Universitas \\ Muhammadiyah Yogyakarta, Bantul, DI Yogyakarta, Indonesia. \\ 2)Program Studi Magister Keperawatan Pasca Sarjana, Universitas Muhammadiyah Yogyakarta, Bantul, DI Yogyakarta, \\ Indonesia \\ Corresponding author : Ivanna Beru Brahmana \\ E-mail : ivanna@umy.ac.id
}

Diterima 03 Februari 2021, Direvisi 18 Februari 2021, Disetujui 20 Februari 2021

\begin{abstract}
ABSTRAK
Masalah: Jenis KB Intra Uterine Device (IUD) merupakan metode KB Jangka Panjang (MKJP) yang banyak dipilih akseptor. Kebutuhan evaluasi pemakaian IUD diperlukan akseptor untuk mengetahui risiko ataupun keluhan yang dirasakan. Tujuan: melakukan evaluasi pemakaian IUD interval di masa pandemi ini dengan menjaga protokol kesehatan. Metode: Bentuk pengabdian berupa: 1. Penyuluhan tentang IUD dan kemungkinan keluhan yang dirasakan oleh akseptor secara online melalui media whatsapp (wa), sekaligus koordinasi kegiatan; 2. Anamnesis ada tidaknya keluhan keputihan dan memeriksa posisi IUD dengan pemeriksaan USG; dan 3. Penjelasan terhadap keluhan dan hasil pemeriksaan. Keluhan akseptor disampaikan dalam anamnesis yang dilakukan sebelum pemeriksaan, dan penjelasan dilakukan setelah pemeriksaan, sekaligus edukasi dan motivasi pada akseptor sesuai keluhan dan hasil pemeriksaan. Pelaksanaan pengabdian dengan mematuhi protokol kesehatan, sehingga maksimal lima akseptor per hari pemeriksaan. Pengabdian dilakukan bertahap, hingga 27 akseptor IUD interval yang mendaftar sebagai peserta pengabdian seluruhnya terlayani. Hasil: Keluhan keputihan dirasakan oleh $48,1 \%(13 / 27)$ peserta, posisi IUD tetap berada dengan baik di dalam rahim didapatkan $92,6 \%(25 / 27)$ peserta, seluruh peserta 100\% (27/27) merasa nyaman dan menyatakan pengabdian ini bermanfaat. Kesimpulan: Pengabdian di masa pandemi tetap bisa dilakukan dengan menjaga protokol kesehatan. Pengabdian pemeriksaan IUD interval dirasakan sangat bermanfaat bagi para peserta di masa pandemi.
\end{abstract}

Kata kunci: akseptor; IUD interval; keputihan; pandemi.

\begin{abstract}
Problem: Type of FP Intra-Uterine Device (IUD) is a long-term family planning method (MKJP). The need to evaluate the use of the IUD requires acceptors to determine the risk of complaint that is felt. Aim: To evaluate the use of IUDs during this pandemic has been done by maintaining health protocols. Methode: The service includes 1 . Counseling about IUDs and possible complaints felt by online via WhatsApp (wa); 2 . Anamnesis whether there are complaints of vaginal discharge and check the position of the IUD by ultrasound examination; and 3. Explanation of complaints and examination results. The acceptor's complaint is carried out before the examination, but after examination is the explanation. The service implementation adheres to health protocols so maximum acceptors is five per day of examination. The service up to 27 interval IUD acceptors who registered as community service participants. Results: Complaints of vaginal discharge were $48.1 \%$ (13/27) of participants. And also, the IUD position remained well in the womb were $92.6 \%$ (25/27) of participant. All participants $100 \%$ (27/27) felt comfortable and expressed used devotion. Conclusion: The service of interval IUD examinations was felt to be very beneficial for participants during a pandemic.
\end{abstract}

Keywords: acceptor; interval IUD; vaginal discharge; pandemic.

PENDAHULUAN

Laju pertumbuhan penduduk (LPP) di Indonesia hingga tahun 2015 sebesar 1,43\% (Badan Pusat Statistik, 2018). Data World Population Data Sheet menyebutkan bahwa Indonesia menduduki urutan keempat sebagai negara dengan jumlah penduduk terbanyak di dunia. Urutan tiga besar adalah China, India, dan Amerika Serikat (PoPulation RefeRence BuReau, 2012). Keluarga Berencana (KB) digalakkan guna menekan pertambahan penduduk. Metode KB Jangka Panjang (MKJP) ada dua jenis yaitu intra uterine device (IUD) dan implan/susuk. Cakupan KB IUD di Indonesia 
sebesar 7,3\% dan implan/susuk sebesar 6,21\% yang dilaporkan tahun 2015 (Budiarti I, Nuryani DD, 2017).

Masa pandemi yang terjadi saat ini menerapkan protokol kesehatan pencegahan Covid-19 dengan dilarang keluar dari rumah bila tidak ada keperluan penting, yang disebut dengan stay at home. Saat keluar rumah pun dilarang berkerumun atau berkumpul, dan menjaga jarak minimal 1-2 meter, yang dikenal dengan istilah social distancing. Dengan adanya pandemi Covid-19 terasa pilihan jenis MKJP lebih tepat, karena berkunjung ke tempat pelayanan kesehatan tidak terlalu dekat. Dalam pengabdian ini dari MKJP yang ada dipilih hanya pada akseptor IUD. Hal ini berbeda dengan pengabdian yang dilakukan oleh Setiawati E. dkk, dengan melakukan pengabdian IUD dan implan, yang dihadiri 42,3\% (11/26) akseptor IUD dan 57,7\% (15/26) akseptor implan/susuk (Setiawati E, Sundari, 2019).

Kenyataan yang ada dalam kondisi pandemi ini menyebabkan akseptor IUD raguragu untuk melakukan kontrol pemakaian IUD yang selama ini dipakai, padahal di satu sisi terdapat kemungkinan keluhan pada akseptor. Hal ini menimbulkan ide dilakukan kegiatan pengabdian untuk mengevaluasi pemakaian IUD akseptor terhadap ada tidaknya keluhan keputihan dan memeriksa posisi IUD.

Untuk itu kami menjembataninya dengan pelaksanaan pengabdian ini dengan tetap memberlakukan protokol kesehatan, di mana jumlah peserta setiap kali pemeriksaan dibatasi maksimal lima orang, dan seluruh peserta terfasilitasi gratis dalam kegiatan ini. Peserta pengabdian adalah akseptor IUD yang berdomisili di sekitar kampus Universitas Muhammadiyah Yogyakarta (UMY) dan RS AMC Muhammadiyah Yogyakarta. Dengan demikian diharapkan peserta pengabdian tidak terlalu jauh ke luar dari rumah, dikarenakan daya tempuh ke tempat pengabdian tidak jauh, sehingga tidak merepotkan. Oleh karena peserta pengabdian tidak mendapatkan kompensasi pengganti biaya transport, namun semua evaluasi diberikan gratis, termasuk biaya pendaftaran di rumah sakit. Protokol kesehatan tidak diijinkan berkerumun juga difasilitasi tim pengabdi dengan koordinasi kegiatan dengan menggunakan media sosial whatsapp (wa).

\section{METODE}

Pengabdian masyarakat yang dilakukan di masa pandemi ini tetap menjaga protokol kesehatan. Dengan demikian akan terjaga keamanan baik bagi tenaga keehatan selaku tim pengabdi, maupun peserta pengabdian. Pelaksanaan pengabdian berupa tiga bentuk kegiatan, yaitu: 1. Penyuluhan tentang IUD dan kemungkinan keluhan yang dirasakan oleh akseptor secara online melalui media whatsapp (wa), sekaligus koordinasi kegiatan; 2. Pemeriksaan IUD dengan melakukan pemeriksaan USG; dan 3. Penjelasan terhadap keluhan dan hasil pemeriksaan, sekaligus sebagai sarana edukasi dan motivasi.

Tahapan yang dilakukan dalam pelaksanaan pengabdian ini bila dijabarkan adalah:

1. Perencanaan

Perencanaan kegiatan perlu dilakukan dengan matang mengingat kondisi masa pandemi saat ini. Tim pengabdi melakukan koordinasi internal antar tim pengabdi, dan eksternal dengan peserta pengabdian dan sarana pelayanan kesehatan yang digunakan. Penentuan tema kegiatan, sasaran peserta, jumlah peserta, waktu dan tempat pelaksanaan, teknik pelaksanaan khusus di masa pandemi dengan menjaga protokol kesehatan, merupakan hal yang diperhatikan dan dipertimbangkan oleh tim pengabdi demi terlaksananya kegiatan dengan aman dan lancar.

Tema kegiatan yang dipilih tentang evaluasi pemakaian IUD untuk menilai keluhan dan risiko pemakaian IUD. Tema ini dipilih dikarenakan kemungkinan banyak akseptor IUD yang terhalang untuk kontrol IUD dikarenakan masa pandemi ini. Di lain pihak kemungkinan terdapat keluhan dari akseptor yang sebenarnya perlu ditindaklanjuti. Kemudahan koordinasi antara tim pengabdi dan peserta dilakukan melalui grup wa. Penjelasan dan informasi yang perlu dilakukan oleh peserta pengabdian diberikan melalui media wa tersebut, supaya pelaksanaan pengabdian berjalan lancar. Peserta diberikan penjelasan tentang tatalaksana pelaksanaan pengabdian, di mana tiap pelaksanaan pemeriksaan yang dilakukan di RS maksimal hanya lima peserta pengabdian tiap harinya. Untuk itu lama pelaksanaan pengabdian dialokasikan selama dua minggu. Waktu dan tempat pelaksanaan kegiatan dilakukan selama dua minggu di Poliklinik Obstetri \& Ginekologi (Obsgin) RS AMC Muhammadiyah Yogyakarta.

2. Implementasi

Pengabdian masyarakat terlaksana dengan aman dan lancar dengan tiga jenis kegiatan, yaitu: 1. Penyuluhan 
tentang IUD dan kemungkinan keluhan yang dirasakan oleh akseptor secara online melalui media wa, sekaligus koordinasi kegiatan; 2. Pemeriksaan posisi IUD dengan melakukan pemeriksaan USG; dan 3. Penjelasan terhadap keluhan dan hasil pemeriksaan. Keluhan akseptor disampaikan dalam anamnesis yang dilakukan sebelum pemeriksaan, dan penjelasan dilakukan setelah pemeriksaan, sekaligus edukasi dan motivasi pada akseptor sesuai keluhan dan hasil pemeriksaan masing-masing akseptor.

Kegiatan pertama berupa koordinasi kegiatan dan penyuluhan tentang IUD dan kemungkinan keluhan yang dirasakan akseptor dan tatalaksana urutan kegiatan yang akan dilakukan dalam pengabdian. Kegiatan ini dilakukan secara online melalui media wa, dimana tim pengabdi dan seluruh peserta pengabdian dimasukkan dalam grup wa oleh admin. Kegiatan dilakukan sejak $\mathrm{H}-2$ sebelum pelaksanaan pemeriksaan. Kegiatan penyuluhan IUD dilakukan oleh narasumber sekaligus pengabdi oleh dr. Ivanna Beru Brahmana, SpOG(K) dan Shanti Wardaningsih, Ph.D pada hari Sabtu, 26 September 2020. Peserta mendaftar dan memilih hari sendiri sesuai dengan hari yang ditawarkan tim pengabdi. Dengan demikian ketaatan peserta untuk hadir sesuai dengan kesediaannya dapat terlaksana dengan baik, dan kegiatan diharapkan berjalan lancar.

Kegiatan kedua adalah anamnesis ada tidaknya keluhan keputihan pada akseptor sebagai efek samping pemakaian IUD dan pemeriksaan USG untuk mengetahui posisi IUD. Kegiatan kedua dilaksanakan selama dua minggu mulai hari Senin, 28 September 2020 sampai dengan Sabtu 10 Oktober 2020. Peserta yang hadir maksimal lima orang tiap hari kegiatan, sesuai dengan daftar yang sudah disepakati. Kegiatan ini dilakukan di Poliklinik Obstetri \& Ginekologi (Obsgin) RS AMC Muhammadiyah Yogyakarta. Anamnesis dan pemeriksaan USG dilakukan oleh Dokter Spesialis Obsgin RS AMC Muhammadiyah Yogyakarta, yaitu: dr. Ivanna Beru Brahmana, SpOG(K), sekaligus pengabdi dalam kegiatan ini. Peserta pengabdian sebanyak 27 orang, telah menandatangani informed consent sebagai persetujuan dilakukan pemeriksaan, setelah mendapat penjelasan dari tim pengabdi.

Kegiatan ketiga sebagai kegiatan terakhir berupa penjelasan terhadap hasil pemeriksaan yang telah dilakukan, sekaligus pemberian edukasi dan motivasi sebagai kegiatan penguat dalam pengabdian ini.

Pelaksanaan pengabdian dalam bentuk diagram alir adalah sebagai berikut:

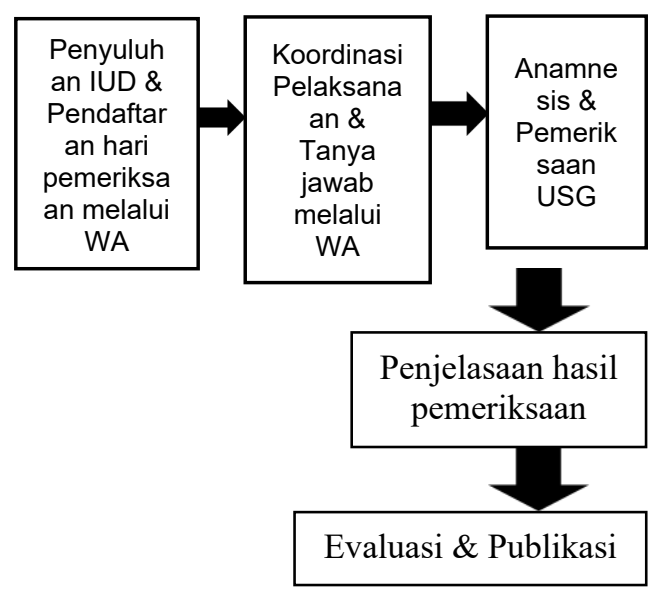

Pengabdi membuat grup wa untuk seluruh peserta pengabdian. Penyuluhan tentang IUD serta pendaftaran hari yang dipilih oleh masingmasing peserta melalui wa tersebut. Pendaftaran dibatasi lima peserta tiap harinya. Koordinasi pelaksanaan pengabdian dan kemungkinan pertanyaan yang disampaikan oleh peserta juga dilakukan dengan wa tersebut. Pelaksanaan pengabdian berupa anmanesis dan pemeriksaan USG pada peserta dilakukan berdasarkan daftar yang sudah disepakati. Setiap selesai kegiatan, kepada tiap peserta langsung diberikan penjelasan terhadap hasil pemeriksaan oleh pengabdi. Peserta diperkenankan berkonsultasi sesuai dengan permasalahan yang dirasakan. Setelah seluruh peserta pengabdian dilayani, dilakukan evaluasi kegiatan dengan seluruh peserta melalui grub wa yang telah dibuat tersebut. Hal-hal yang ingin ditanyakan peserta dipersilakan ditanyakan lewat grub ataupun secara personal pada penagbdi. Setelah dirasakan cukup, pengabdi tak lupa mengucapkan terimakasih atas kesediaan seluruh peserta mengikuti kegiatan pengabdian dengan tertib dan menjaga protokol kesehatan. Naskah publikasi disusun sebagai luaran pengabdian. 


\section{HASIL DAN PEMBAHASAN}

Seluruh kegiatan pengabdian berjalan dengan aman dan lancar dengan tetap memperhatikan protokol kesehatan pencegahan penularan Covid-19. Perencanaan kegiatan berupa pendaftaran peserta, penyuluhan dan koordinasi kegiatan yang dilakukan secara online dipahami dengan baik oleh peserta. Apabila ada peserta yang belum paham tentang alur pelaksanaan kegiatan, mulai dari pendaftaran sampai pemeriksaan ataupun ingin berganti hari pemeriksaan yang sudah didaftarkan sebelumnya, diberikan kesempatan terbuka, sehingga peserta merasa nyaman. Kegiatan perencanaan ini menghasilkan 27 peserta pengabdian yang akan mengikuti penyuluhan dan evaluasi IUD yang dipakainya sesuai dengan daftar hari pelaksanaan kegiatan yang telah didaftarkan sendiri oleh peserta. Setiap hari pelaksanaan kegiatan hanya diisi oleh lima peserta yang akan dievaluasi tentang IUD yang dipakainya, demi menjaga protokol kesehatan yang diterapkan.

Pelaksanaan pengabdian berupa tiga kegiatan yang dijalankan, yaitu: 1. Penyuluhan tentang IUD dan kemungkinan keluhan yang dirasakan oleh akseptor secara online melalui media whatsapp (wa), sekaligus koordinasi kegiatan; 2. Pemeriksaan IUD dengan melakukan pemeriksaan USG; dan 3 . Penjelasan terhadap keluhan dan hasil pemeriksaan, sekaligus sebagai sarana edukasi dan motivasi.

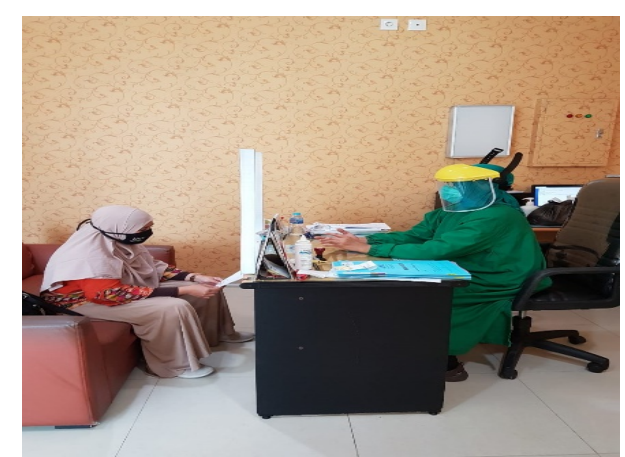

Gambar 1. Anamnesis keluhan akseptor Sumber: dokumen penulis.

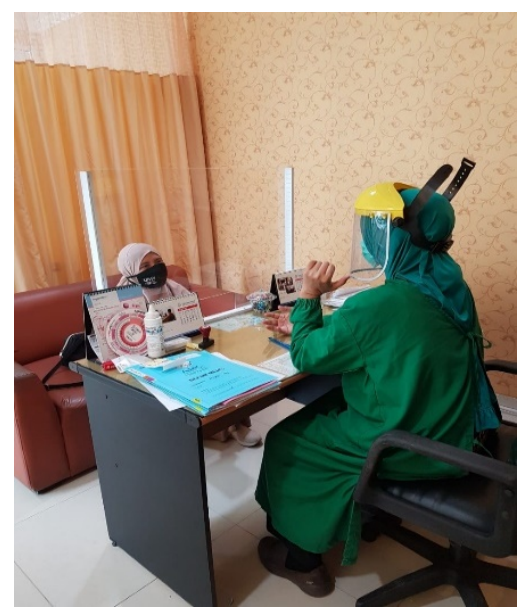

Gambar 2. Penjelasan hasil pemeriksaan Sumber: dokumen penulis

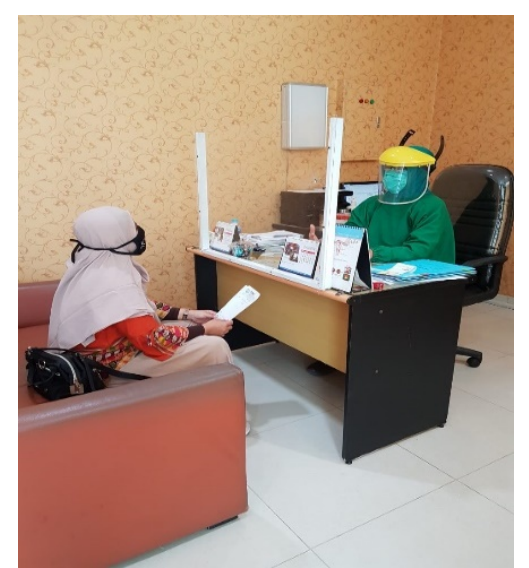

Gambar 3. Edukasi \& motivasi pada akseptor. Sumber: dokumen penulis

Ketiga gambar di atas adalah foto-foto kegiatan pengabdian yang diambil dari dokumen penulis. Gambar 1 menunjukkan anamnesis yang dilakukan pada akseptor IUD sebelum pemeriksaan. Gambar 2 menunjukkan penjelasan yang dilakukan pengabdi setelah pemeriksaan USG. Gambar 3 menunjukkan edukasi dan motivasi dari pengabdi pada akseptor sehingga IUD akan terus dipakai dengan nyaman. 
Tabel 1. Rincian peserta pengabdian

\begin{tabular}{lcc}
$\begin{array}{l}\text { Peserta Pengabdian } \\
\text { Jumlah anak: }\end{array}$ & Pumlah(n) \\
\hline $\mathbf{1}$ & 4 & 14,8 \\
\hline $\mathbf{2}$ & 15 & 55,6 \\
\hline $\boldsymbol{> = 3}$ & 8 & 29,6 \\
\hline & & \\
\hline Jumlah kontrol: & & 33,3 \\
\hline Belum pernah & 9 & 33,3 \\
\hline $\mathbf{1 - 2}$ & 9 & 33,3 \\
\hline >=3 & 9 & \\
\hline Hasil anamnesis: & & 48,1 \\
\hline Keputihan & 13 & 51,9 \\
\hline Tidak keputihan & 14 & \\
\hline Hasil pemeriksaan USG: & & \\
\hline Posisi IUD baik & 25 & 92,6 \\
\hline Posisi IUD bergeser & 2 & 7,4 \\
\hline Total & 27 & 100,00 \\
\hline
\end{tabular}

Tabel 1 menampilkan rincian peserta pengabdian berupa jumlah anak, jumlah berapa kali kontrol selama menggunakan IUD, serta hasil anamnesis dan pemeriksaan USG. Peserta pengabdian terbanyak mempunyai jumlah anak dua orang sebesar 55,6\% (15/27), diikuti jumlah anak tiga orang atau lebih sebesar 29,6\% (8/27), dan hanya memiliki satu anak sebesar $14,8 \%(4 / 27)$. Jenis KB IUD ini merupakan metode KB jangka panjang, yang biasanya dipilih oleh akseptor yang cukup anak, disini tampak IUD lebih banyak dipilih oleh mereka punya anak dua atau lebih. Jenis KB IUD ini lebih jarang dipilih oleh akseptor dengan jumlah anak baru satu, dikarenakan akseptor masih menginginkan menambah anak. Hal ini sesuai dengan yang diharapkan, karena IUD merupakan MKJP di mana keinginan menjarangkan anak lebih lama, atau bahkan memang tidak menginginkan kehamilan lagi. $\mathrm{Hal}$ ini sejalan dengan pengabdian yang dilakukan Meilani N. dkk bahwa IUD dipilih oleh ibu yang mempunyai banyak anak (85\%) dibandingkan yang jumlah anaknya lebih sedikit (15\%) (Meilani N, Siregar DA, 2019). Perbedaan dengan pengabdian kami, dalam pengabdian mereka tidak terdapat akseptor dengan satu anak. Jenis KB IUD lebih banyak dipilih oleh akseptor dengan paritas sedang (jumlah anak 2-5) sebanyak 70,8\% (85/120) dibandingkan akseptor dengan paritas rendah (jumlah anak 1) sebesar 29,2\% (35/120) (Purbaningrum P, Hariastuti I, 2019). Susanti dkk menyebutkan bahwa paritas 2-3 terbanyak $47,6 \% \quad(10 / 21)$ yang ikut serta dalam pengabdian (Susanti dan Issusilaningtyas E, 2019).

Jumlah kontrol yang dilakukan oleh akseptor selama menggunakan IUD adalah terbagi rata pada akseptor yang sama sekali belum pernah kontrol sejak IUD dipasang, yang kontrol sebanyak 1-2 kali, dan yang kontrol IUD sebanyak tiga kali atau lebih, yaitu 33,3\% $(9 / 27)$. Dalam hal ini tidak ada perbedaan jumlah kontrol bagi akseptor yang sama sekali belum pernah kontrol, yang kontrol termasuk cukup sebanyak 1-2 kali, yang termasuk kontrol sering yaitu tiga kali atau lebih. Hal ini kemungkinan dikarenakan akseptor yang diikutkan dalam pengabdian ini adalah akseptor IUD interval, dalam arti pemasangan IUD tidak karena setelah melahirkan. Dengan demikian bagi mereka yang tidak pernah kontrol setelah pemasangan, kemungkinan adalah pemasangan IUD kedua atau ketiga, dalam arti akseptor sudah berpengalaman sebelumnya menggunakan IUD sebagai pilihan KB nya. Demikian pula untuk yang kontrol 1-2 kali, atau bahkan kontrol tiga kali atau lebih. Akseptor yang rutin kontrol tersebut dikarenakan memang sebaiknya kontrol IUD ada ataupun tidak ada keluhan, minimal sekali dalam setahun. Apabila terdapat keluhan atau efek samping agar segera diketahui, untuk mengurangi risiko kegagalan IUD.

Kegiatan kedua berupa anamnesis pada peserta pengabdian terhadap keluhan 
keputihan selama menggunakan IUD, didapatkan 48,1\% (13/27) yang mengalami hal tersebut. Akseptor dengan keluhan keputihan maupun tanpa keluhan keputihan hampir berimbang, walaupun masih lebih banyak akseptor yang tidak mempunyai keluhan keputihan. Hal ini disebabkan karena IUD merupakan benda asing di daerah kemaluan, sehingga kemungkinan mudah terjadinya keluhan keputihan. Untuk itu kontrol pada akseptor IUD setidaknya sekali dalam setahun sangat dianjurkan. Apabila didapatkan keluhan keputihan seperti ini, supaya segera ditindaklanjuti, sehingga keluhan tersebut tidak berkembang menjadi penyakit yang tidak diharapkan. Sejalan dengan pengabdian yang dilakukan Perwitasari T. menunjukkan bahwa $85 \%$ akseptor memahami efek samping penggunaan IUD (Perwitasari T, 2020). Efek samping keputihan didapatkan sebesar $44,62 \%$ (29/65) pada pengabdian yang diselenggarakan oleh Zannah I.R. dkk (Zannah IR, Maryati I, 2020).

Hasil pemeriksaan USG tentang posisi IUD didapatkan bahwa IUD dengan posisi baik sebanyak $92,6 \%(25 / 27)$, dan ada dua peserta dengan IUD bergeser sebesar 7,4\% (2/27). Bila didapatkan 100 akseptor IUD, berarti sekitar 7 akseptor yang mengalami posisi IUD bergeser. Temuan seperti inilah yang menjadikan kontrol pada akseptor IUD merupakan hal penting. Dengan mengetahui posisi IUD bergeser, maka IUD harus dilepas. Bila tidak dilepas, akseptor merasa memakai KB, dan berisiko yang disebut dengan 'gagal KB', hingga besar kemungkian terjadi kehamilan pada akseptor tesebut.

Berbeda dengan pengabdian yang dilakukan oleh Widodo $\mathrm{S}$. dkk, dengan melakukan penyuluhan efek samping pada IUD antara lain tentang benang yang hilang dan adanya pengeluaran cairan dari vagina atau dicurigai adanya penyakit radang panggul (PRP). Pada pengabdian tersebut, bila didapatkan benang yang hilang, maka posisi IUD disarankan dengan pemeriksaan USG (Widodo S dan Hasanah N, 2018).

Alasan Tidak Kontrol Setelah Pemasangan

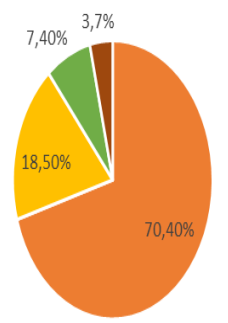

- Tidak ada keluhan $\|$ Malas "Renot Malu

Gambar 4. Alasan tidak kontrol setelah pemasangan
Gambar 4 menampilkan alasan akseptor belum pernah memeriksakan atau kontrol IUD setelah pemasangan. Alasan terbanyak akseptor tidak kontrol adalah merasa tidak ada keluhan $70,4 \%$ (19/27), malas $18,5 \%$ $(5 / 27)$, repot $7,4 \%(2 / 27)$, dan malu bila harus dilakukan pemeriksaan ginekologi 3,7\% (1/27).

Akseptor IUD interval adalah akseptor yang sudah mempunyai pengalaman memakai IUD sebelum pemasangan IUD yang saat ini digunakan. Dengan demikian pengalaman pemakaian selama ini merasa nyaman dan tidak ada keluhan menjadikan akseptor tidak berkeinginan memeriksakan diri. Pengalaman pemakaian IUD sebelumnya juga yang menjadikan akseptor malas datang kontrol, di mana kemungkinan harus mengantri di tempat pemeriksaan. Alasan repot menjadi alasan ketiga, kemungkinan dengan banyaknya aktifitas yang harus dilakukan telah menyita waktu akseptor. Hal ini pula yang menyebabkan akseptor memilih MKJP, dimana tidak perlu harus terlalu sering datang kontrol pada dokter atau bidan. Alasan malu dikarenakan di tempat pelayanan IUD dimana tidak tersedia USG, maka posisi IUD diperiksa dengan melakukan pemeriksaan ginekologi, yaitu pemeriksaan dengan alat membuka kemaluan akseptor. Pengabdian ini menawarkan pemeriksaan dengan USG saat memeriksa posisi IUD, dengan demikian kemungkinan hal ini pula yang menjadikan cukup antusiasnya akseptor mendaftar sebagai peserta pengabdian. Di samping menjadi jembatan kegalauan bila datang ke tempat pelayanan kesehatan di masa pandemi, karena dalam pengabdian ini telah disampaikan akan tetap dijaga sesuai protokol kesehatan pencegahan penularan Covid-19, dengan membatasi jumlah pemeriksaan maksimal hanya lima peserta per hari kegiatan pengabdian. Pemakaian masker, pemakaian handsanitizer menjadi hal wajib yang harus dipatuhi. 


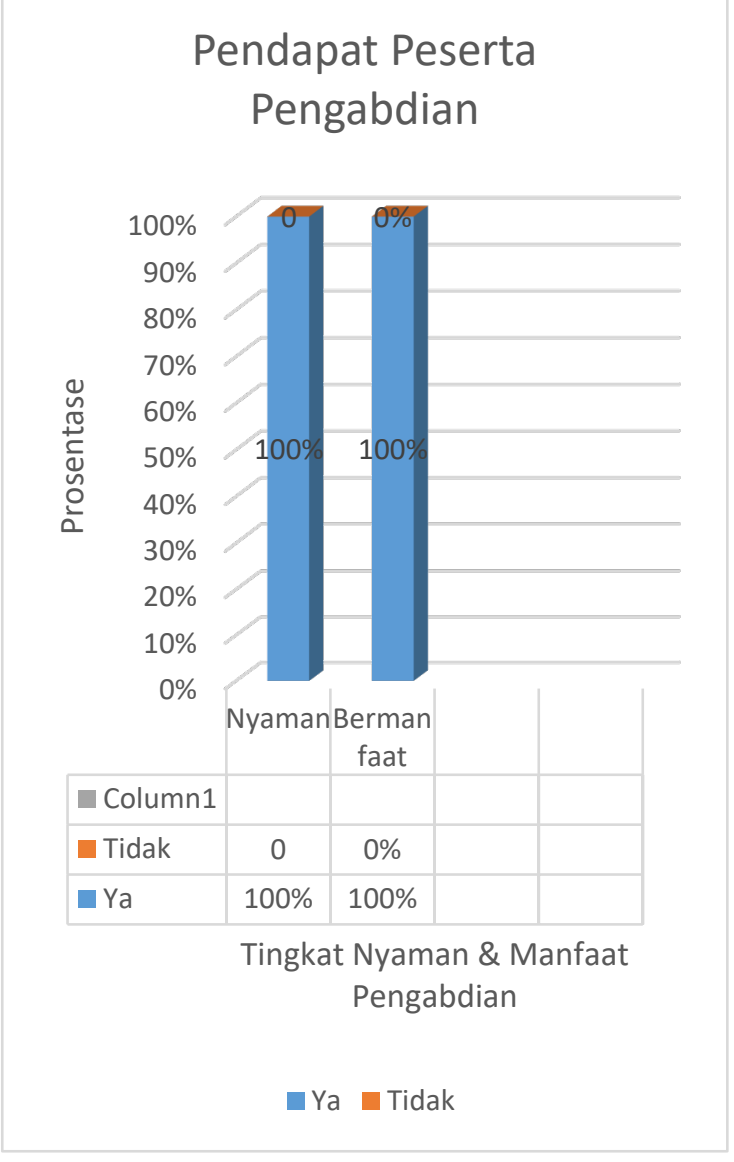

Gambar 5. Pendapat peserta terhadap evaluasi pengabdian

Gambar 5 menampilkan pendapat peserta pengabdian tentang pelaksanaan pengabdian yang harus bertahap hingga dua minggu, di mana akhirnya semua peserta terlayani. Seluruh peserta maklum dan tetap nyaman dengan pelaksanaan pengabdian bertahap, dilakukan secara online dalam grup wa, bahkan koordinasipun dilakukan secara online. Seluruh peserta $100 \%(27 / 27)$ tetap merasa nyaman dan merasa paham dengan alur yang disampaikan secara online melalui wa. Dengan demikian semua peserta berupaya taat datang sesuai jadual yang sudah mereka pilih dalam daftar hari kegiatan yang ditawarkan, dan mendukung terlaksananya kegiatan pengabdian berjalan aman dan lancar.

Pendapat peserta pengabdian terhadap bermanfaat tidaknya kegiatan pengabdian ini juga ditampilkan dalam diagram 2 tersebut. Seluruh peserta 100\% (27/27) menyatakan pengabdian ini sangat bermanfaat. Rasa khawatir bagi para akseptor bila tidak kontrol, namun sedang masa pandemi, mereka merasa difasilitasi untuk mengetahui keadaan IUD mereka, namun tidak melanggar protokol kesehatan pencegahan penularan Covid-19.
Seluruh peserta menyatakan puas dengan kegiatan pengabdian yang diselenggarakan.

\section{SIMPULAN DAN SARAN}

Kegiatan pengabdian masyarakat yang berjudul "Pengabdian Evaluasi Akseptor IUD Interval di Masa Pandemi" berjalan aman dan lancar. Keluhan keputihan dirasakan oleh $48,1 \%$ (13/27) peserta, posisi IUD tetap berada dengan baik di dalam rahim didapatkan $92,6 \%$ (25/27) peserta, seluruh peserta 100\% (27/27) merasa nyaman dan menyatakan pengabdian ini bermanfaat. Pengabdian serupa diharapkan bisa dilaksanakan di masa mendatang, dan semoga masa pandemi sudah berlalu, sehingga bisa dilakukan pada peserta yang lebih banyak.

\section{UCAPAN TERIMAKASIH}

Tim pengabdi mengucapkan terimakasih yang tulus kepada: RS AMC Muhammadiyah Yogyakarta, sebagai tempat pelaksanaan pengabdian, seluruh bidan yang bertugas di poliklinik Obsgin RS AMC Muhammadiyah Yogyakarta pada saat pengabdian ini dilaksanakan, yang telah membantu terlaksananya pengabdian, serta seluruh peserta pengabdian yang telah hadir dengan tertib dan menjaga protokol kesehatan sesuai yang dianjurkan dalam kegiatan ini.

\section{DAFTAR RUJUKAN}

Badan Pusat Statistik. (2018). Proyeksi Penduduk Indonesia 2015-2045: Hasil SUPAS 2015. In Badan Pusat Statistik.

Budiarti I, Nuryani DD, H. R. (2017). Determinan Penggunaan Metode Kontrasepsi Jangka Panjang (MKJP) pada Akseptor KB. Jurnal Kesehatan, VIII(2), 220-224.

Meilani N, Siregar DA, M. F. (2019). Pemasangan Kontrasepsi Implan dan Alat Kontrasepsi dalam Rahim di Dusun XVIII Kecamatan Percut Sei Tuan. Jurnal Pengabdian Masyarakat. Jurnal Pengabdian Masyarakat: Darma Bakti Teuku Umar, 1(1), 190-198.

Perwitasari T. (2020). Edukasi tentang Keuntungan Menggunakan KB IUD di Kelurahan Bagan Pete Kota Jambi. Jurnal Abdimas Kesehatan (JAK), 2(2), 104-108.

PoPulation RefeRence BuReau. (2012). 2012 World population datasheet. In Www.Prb.Org.

Purbaningrum P, Hariastuti I, W. A. (2019). Analisis Faktor Rendahnya Penggunaan Kontrasepsi Intra Uterine Device (IUD) di Jawa Timur 2015. Jurnal Biometrika dan Kependudukan. 
Jurnal Biometrika Dan Kependudukan, 8(1), 52-61.

Setiawati E, Sundari, N. I. (2019). Deteksi Dini Pemakaian MKJP (Metode Kontrasepsi Jangka Panjang) Pada Wanita Usia Subur Di Desa Candirejo Mijen Kab.Semarang. Jurnal Pengabdian Dharma Bakti, 2(2), 13-19.

Susanti dan Issusilaningtyas E. (2019). Peningkatan Pengetahuan Tentang Alat Kontrasepsi Peningkatan Pengetahuan Tentang Alat Kontrasepsi Intra Uterin Device (IUD) dan Suntik dengan Pemberdayaan Wanita Usia Subur di Posyandu RW 11 Kelurahan Sidanegara Cilacap. Jurnal Pengabdian Masyarakat Al-Irsyad, 1(1), 29-37.

Widodo S dan Hasanah N. (2018). Penyuluhan Program Keluarga Berencana Di Posyandu Melati IV Kelurahan Rambutan Kecamatan Ciracas Jakarta Timur. Jurnal Pelayanan Dan Pengabdian Masyarakat, 2(2), 29-37.

Zannah IR, Maryati I, W. R. (2020). Gambaran Keluhan-keluhan Akibat Penggunaan Alat Kontrasepsi IUD pada Akseptor IUD di Wilayah Kerja Puskesmas Sukajadi Kota Bandung. 